\title{
Review
}

\section{Bacteria and the growing threat of multidrug resistance for invasive cardiac interventions}

\author{
Grant N. Pierce ${ }^{1, *}$, Craig Resch ${ }^{1}$, Muntahi Mourin $^{1}$, Pavel Dibrov², Elena Dibrov ${ }^{1}$, \\ Amir Ravandi 1,3
}

${ }^{1}$ Department of Physiology and Pathophysiology, Rady Faculty of Health Sciences, Institute of Cardiovascular Sciences, Albrechtsen Research Centre, St. Boniface Hospital, Winnipeg, MB R2H 2A6, Canada

${ }^{2}$ Department of Microbiology, Faculty of Science, University of Manitoba, Winnipeg, MB R3T 2N2, Canada

${ }^{3}$ Department of Internal Medicine, Rady Faculty of Health Sciences, University of Manitoba, Winnipeg, MB R3E 0W3, Canada

*Correspondence: gpierce@sbrc.ca (Grant N. Pierce)

Academic Editors: Morris Karmazyn and Victor L. Serebruany

Submitted: 5 October 2021 Revised: 9 December 2021 Accepted: 20 December 2021 Published: 14 January 2022

\begin{abstract}
Invasive cardiovascular procedures which include heart transplantations, congenital heart surgery, coronary artery bypass grafts, cardiac valve repair and replacement, and interventional cardiac electrophysiology procedures represent common mechanisms to treat a variety of cardiovascular diseases across the globe. The majority of these invasive approaches employ antibiotics as a regular and obligatory feature of the invasive procedure. Although the growing incidence of bacterial resistance to currently used antibiotics threatens to curtail the use of all interventional surgical techniques, it remains an underappreciated threat within the arsenal of cardiovascular therapies. It is reasonable to expect that the continued overuse of antibiotics and the frequent management of coronavirus disease 2019 (COVID-19) infected patients with high doses of antibiotics will inevitably accentuate the rise of multidrug resistance. The purpose of this article is to heighten awareness of the role of bacterial infections in cardiovascular disease, the use of antibiotics in today's cardiovascular surgical theaters, the threat facing cardiovascular surgery should multidrug resistance continue to rise unabated, and the development of new antibiotic platforms to solve this problem.
\end{abstract}

Keywords: Bacteria; Cardiovascular disease; Antibiotics; Surgery; Cardiovascular intervention; Multidrug resistance; COVID-19

\section{Cardiac surgery and the associated bacterial infections}

Although life style, diet and behavioural changes play an increasingly important therapeutic and preventative role in cardiovascular disease (CVD) [1], cardiac surgery remains a valuable and integral clinical tool to address heart and vascular disease. It is not a coincidence that invasive cardiovascular surgical procedures became prominent in the 1920's at about the same time that antibiotics were developed. Generally, the primary forms of cardiovascular invasive procedures used today are heart transplantation, congenital heart disease, coronary artery bypass grafts (CABG), percutaneous coronary artery interventions (PCI), cardiac valve repair and replacement, and interventional cardiac electrophysiology procedures (Table 1, Ref. [2-9]). Just these invasive cardiac surgical procedures total about 2 million per year in the USA alone. Without antibiotics to combat the bacterial infections that inevitably accompany these surgeries (with the exception of PCI in which infection is not common), their valuable life saving utility would not be possible.

The types of bacterial species found to infect patients during cardiovascular surgery are varied. Staphylococcus aureus, particularly the methicillin-resistant type (MRSA), has received the most research and clinical attention due to its prevalence and the clinical challenges it generates. However, many other bacterial species are of concern in cardiovascular sugery (Table 2). A recent systematic review of 12 studies documented the presence of Yersinia sp. in infective endocarditis, most commonly in the mitral valve but also in the aortic valve [10]. Aminoglycosides, cephalosporins and quinolones were used to deter the fever, sepsis and heart failure that was found to accompany these Yersinia infections [10]. Corynebacterium jeikeium has also been found as a rare cause of infective endocarditis [11]. Actinetobacter baumannii and Actinetobacter calcoaceticus complexes are becoming a serious problem in intensive care units, particularly as these species become increasingly resistant to conventional antibiotic therapy. Actinetobacter iwoffii has also been identified as an infective species. The aortic valve was most commonly involved. Aminoglycosides, cephalosporins and carbapenems were the usual antibiotic therapy administered. A combination of a cephalosporin and an aminoglycoside was used in $78.5 \%$ of the cases in one study [12]. The antibiotic therapy was successful in $70.3 \%$ of the cases and overall mortality was $32.4 \%$ [13]. An invasive species of Enterobacter cloacae has been identified in transplant recipients [14] as has Nocardia bacteraemia [15]. In over 1000 clinical samples collected from patients suspected of heart infections, $57 \%$ contained gram 
Table 1. The most common invasive cardiac interventions in use today in the USA.

\begin{tabular}{lcc}
\hline Surgical Intervention & Annual Incidence of Use & Year Introduced \\
\hline Heart Valves & 182,000 & 1923 \\
Congenital heart disease & & 1938 \\
Cardiac Electrophysiology Pacemakers & $>100,000$ & 1958 \\
CABG & 519,000 & 1960 \\
Cardiac Transplants & 2000 & 1967 \\
PCI & 965,000 & 1977 \\
TAVR & 130,000 & 2002 \\
Total cardiovascular surgeries/yr & $1,898,000$ & \\
\hline
\end{tabular}

Data are from references [2-9]. CABG, coronary artery by-pass graft; PCI, percutaneous coronary intervention; TAVR, transcatheter aortic valve replacement.

Table 2. Common and rare pathogens identified in cardiac surgeries.

\begin{tabular}{lc}
\hline Staphylococcus aureus & Actinetobacter baumannii \\
Actinetobacter calcoaceticus & Actinetobacter iwoffii \\
Enterobacter cloacae & Nocardia bacteraemia \\
Escherichia coli & Klebsiella pneumoniae \\
Rothia aeria & Rothia dentocariosa \\
Yersinia sp (Y. pestis, Y. enterocolitica and Y. pseudotuberculosis) \\
Corynebacterium jeikeium & $\beta$-lactamase \\
\hline
\end{tabular}

negative bacterial growth [16]. Of the 109 different gram negative bacteria isolated, $40 \%$ were Escherichia coli, $30 \%$ were Klebsiella pneumoniae [16]. Oral flora like Rothia aeria and Rothia dentocariosa have been recovered from patients during cardiac surgery and have been suggested to be rare but significant causes of infective endocarditis [17].

\section{The current use of antibiotics in cardiovascular surgery}

Antibiotics are required for use in cardiovascular surgery to prevent or treat bacterial infections described above that inevitably occur post-surgery. Catheter-related bloodstream infection is a serious complication associated with increases in morbidity, mortality and escalating health care costs [18]. It is important to recognize that although this is not a cardiac specific problem, it does have an important impact on cardiac surgeries. In a 1990 survey of surgical members of the American College of Chest Physicians, the overwhelming majority of respondents gave prophylactic antibiotics for their invasive cardiovascular procedures and today they are used routinely (Table 3 , Ref $[12,19])$. Infections associated with invasive cardiovascular procedures are not solely a problem for chest surgery.

Mediastinitis is an inflammatory infection of the midchest due to perforation of the esophagus and deep sternal wound infections. It is a serious acute or chronic complication that can accompany every cardiac surgery that involves a sternotomy [20]. Post-operative infections occur at an incidence rate of $1-18 \%$ in children with delayed clo-
Table 3. The frequency of prophylactic antibiotic usage in cardiovascular surgeries.

\begin{tabular}{lc}
\hline Surgical Procedure & $\begin{array}{c}\text { Frequency of } \\
\text { Antibiotic Use (\%) }\end{array}$ \\
\hline Cardiac Valve Surgery & 96 \\
Coronary Artery Bypass Graft Surgery & 91 \\
Electrophysiological Surgical Procedures & 78 \\
Congenital Heart Surgery & routine* $^{*}$ \\
\hline
\end{tabular}

Electrophysiological procedures include pacemakers and defibrillators.

Data are from LoCicero, 1990 [19] and *[12].

sure of the sternum [21]. Increased morbidity and mortality as well as increased costs are associated with postoperative infections [20]. As early as the 1960's, placebocontrolled trials clearly demonstrated the benefits of the use of antibiotic prophylaxis for the treatment and prevention of bacterial infections post cardiac surgery [22,23]. Limiting the use of antibiotics or antibiotic resistance to surgical site infections generally and sternal and mediasternal infections specifically have significant ramifications for both mortality and morbidity, in addition to the economic implications in lengthened hospital stays and extra drug expenses [20,24,25].

The clear benefit of antibiotic administration post cardiac surgery has led to the development of guidelines for the use of antibiotics. These guidelines advise on both the type of antibiotic to use as well as the duration and timing of the intervention. The type and dosages currently recommended for use in the various surgeries has, however, evolved over time and experiencial usage. Over thirty years ago, cardiac surgical procedures used cephalasporins over $89 \%$ of the time. Of these, $57 \%$ were early generation cephalosprins and $32 \%$ were late generation [19]. Penicillin was employed $1.7 \%$ of the time and aminoglycosides $0.7 \%$ [26]. In the 1990's, patients who were allergic to penicillin were administered cephalosporins $44 \%$ of the time, vancomycin $35 \%$, clindamycin $11 \%$ and aminoglycosides $5 \%$ 
of the time [19]. Twenty percent of cardiac surgeries delivered no pre-operative or intra-operative antibiotics. Approximately $35 \%$ of surgeons delivered antibiotics for 4 hours after surgery with $28 \%$ employing a 6-hour duration of delivery [19]. By 1999, 94\% of sugical centers were using first or second generation cephalosporins for perioperative antibiotic therapy for 24 hours, but never exceeding 76 hours [26]. More recently, the most used prophylaxis regiment employed second generation cephalosporins together with aminoglycosides [12].

In postoperative situations, less consensus was apparent. Twenty-nine different antibiotics from 8 subclasses were employed [26]. By 2007, the Society of Thoracic Surgeons Practice Guidelines recommended the use of $\beta$ lactam antibiotics for primary prophylaxis in patients without evidence of methicillin-resistant Staphylococcus aureus (MRSA). However, in MRSA patients, vancomycin was the antibiotic of choice [27]. There appeared to be no difference between the efficacy of different generation cephalosporins as antibiotics, although earlier generation cephalosporins like cefazolin may produce better indications against Staphylococcus sp. infections in cardiac surgery [27]. Up to $30 \%$ of all patients undergoing cardiac surgery have evidence of exposure to Staphylococcus aureus and, therefore, have 3 times the risk of $S$. aureus infections post surgery [28]. Mupirocin has been shown to be an effective antibiotic in these cases [29]. Sixty percent of patients receiving antibiotics were administered these antibiotics for longer than the recommended time of 24-48 hours postoperatively $[30,31]$. Indeed, data would suggest that the prologation of antibiotic usage beyond 48 hours increases the incidence of the rate of infection [12]. The increasing emergence of MRSA infections in recent years has led to more rigorous use of prophylactic vancomycin instead of cephalosporins. Based on extensive CABG data from the USA, vancomycin usage would save over 100 lives, prevent over 3000 surgical site infections and save $\$ 43$ million [27]. Interestingly, a recent report has suggested that methicillin resistance is not a prognostic factor in $S$. aureus infective endocarditis [32].

Pre-operative administration of antibiotics like cephalosporins for 1 hour before skin incision has now been recommended and should be continued for 48 hours after the completion of cardiac surgery [27,29]. Two grams of cefazolin is recommended for patients weighing $>60 \mathrm{~kg}$. A second dose of $1 \mathrm{~g}$ should be administered if the surgical incision remains open in the operating room for surgeries lasting longer than 4 hours [27,29] and was to be delivered every $3-4$ hours. It is clear that antibiotic administration is mandatory in cardiovascular (CV) surgery.

\section{The problem of multidrug resistance is not hypothetical: it's here}

In 2014, The World Health Organization published an extensive report "Antimicrobial resistance: global report on surveillance 2014", officially recognizing the rapid spread of multidrug resistance as a global threat [33]. In 2020, the World Health organization stated that "anti-microbial resistance is one of the top ten global health threats facing humanity" [34]. It is important to put this rather dire prediction in perspective. In the past, the primary causes of death at the turn of the 20th century which continued through its early decades were bacterial in origin - pneumonia, dysentery, enteritis, diphtheria and tuberculosis [35]. These diseases were controlled through the discovery of antibiotics and their eventual regular use in medical practices by the third and fourth decades of that century were major factors in reducing the rates of death and increasing our life span throughout the 20th century and into the present day. Unfortunately, antibacterial resistance was observed [36] soon after the initial discovery of antibiotics in the 1920s and a multidrug resistant bacteria was identified as early as 1955 [37]. Each new class of antibiotics was subsequently followed by the appearance of resistance to them [38]. Drug development became less profitable which led to large pharmaceutical companies leaving the field, further worsening the problem [39].

In 2013, the Center for Disease Control and Prevention (CDC) estimated that 2 million people get ill each year in the United States from antibiotic-resistant infections [40]. By 2019, that estimate had increased to at least 2.8 million antibiotic-resistant infections with more than 23,000 deaths each year [41]. Of note, methicillin-resistant Staphylococcus aureus was identified as one of the "Serious Threats" in this document. In 2018, there were 250,000 resistant bacterial infections in Canada, and more than 5400 directly related deaths [42]. It is predicted that by 2050 about 10 million deaths globally each year will be attributed to bacterial resistance, which will exceed deaths from cancer [43].

Multidrug resistance has economic as well as health implications. It is expensive to develop new antibiotics but it has become apparent that a lack of useful antibiotics is even more expensive [37]. Antibiotic resistance was estimated to cost the Canadian healthcare system $\$ 1.4$ billion/year in 2018 [42]. Canada's Gross Domestic Product (GDP) was estimated to be reduced by $\$ 2$ billion in 2018 due to multidrug resistance [42]. Within less than 10 years, antimicrobial resistance is predicted to drive 24 million people globally into extreme poverty [44]. The costs to the world economy would be expected to exceed $\$ 100$ trillion [43].

\section{The causes of multidrug resistance}

Overuse of antibiotics in therapy for humans, as well as for farm animals and fish in aquaculture is implicated as a major reason for the rapid spread of bacterial multidrug resistance on a global scale. Bacteria, including nonpathogenic bacteria in the environment, are exposed to sublethal concentrations of antibiotics creating a powerful se- 
lective pressure resulting in resistance to multiple antimicrobials [45]. These resistance genes accumulate on plasmids which can be transferred laterally amongst different bacterial species and insures resistance continues to evolve and grow [46].

The molecular basis for the evolution of drug resistance in bacteria has been studied extensively. There are four main mechanisms of resistance. Multidrug resistance in bacteria may be achieved by upregulation of multidrug efflux pumps via random mutations [46,47]. Multidrug efflux pumps are able to extrude a wide variety of compounds making them one of the driving forces behind multidrug resistance [48]. In addition, resistance can be achieved through a decrease in membrane permeability by downregulation of bacterial porins, or via alteration of drug binding sites to deoxyribonucleic acid (DNA) via chromosomal mutations in the ribosome, or, finally, by inactivation of the drug via its modification by aminoglycoside modifying enzymes and $\beta$-lactamases [49].

Over a century ago, the Hemagglutinin Type 1 and Neuraminidase Type 1 (H1N1) influenza $A$ pandemic wreaked havoc on the health of the world. About one third of the world's population died, most likely not due to the influenza virus itself but due to secondary bacterial infections like pneumonia [50-52]. Collonising the lungs with opportunistic pathogenic bacteria like Staphylococcus aureus and Staphylococcus pneumoniae were the likely deadly suspects [44]. With this knowledge in hand, it was suspected that physicians would increase their usage of antibiotics during the current COVID-19 pandemic. Indeed, the overall number of antibiotic prescriptions in the UK during the pandemic increased significantly $(6.71 \%)$ according to National Health Service of England data despite a growing trend since 2014 to reduce the use of antibiotics [53]. Additional preliminary evidence supports the contention that broad spectrum antibiotics are used increasingly during the COVID-19 pandemic [54]. A review of current literature found that $72 \%$ of hospitalized COVID-19 patients received antibiotics, while only $8 \%$ actually demonstrated bacterial or fungal co-infections [55]. A more extensive meta-analysis of antibiotic use in COVID-19 patients demonstrated the prevalence of prescribing antibiotics in COVID-19 patients was 75\% [56]. The prescription of antibiotics was higher with increasing age, higher in those on mechanical ventilation and lower in children [56]. With the estimated incidence of bacterial co-infection at $9 \%$, it is clear that over-prescription of antibiotics is rampant during the current COVID-19 pandemic [56]. Indeed, up to 70\% of antibiotic usage in COVID-19 patients was not indicated clinically [57].

This has led to the inevitable conclusion that the escalating and unnecessary use of high dose antibiotics to curb the current COVID-19 pandemic will accelerate multidrug resistance [52,55]. Significantly, countries like India are already showing disturbing trends. COVID-19 and secondary bacterial co-infection rates were higher and resulted in an increased incidence of death [58]. It is, therefore, again reasonable to expect that the estimates of the rise of bacterial resistance to antibiotics created prior to the COVID-19 pandemic may have underestimated the time line of its impact on health care in the coming years.

It is important, however, to recognize that these data and the concerns about antibiotic overuse are dependent upon the period studied and the country investigated. A recent study of antibiotics usage in 204 countries revealed a $46 \%$ increase in the daily consumption of antibiotics globally from 2000 to 2018 [59]. The specific country examined influenced usage significantly ( 9 fold) from its low in the Philippines to a high of 46 defined daily doses of antibiotics per 1000 population in Greece [59]. This likely reflects differences in admission procedures, hospital capabilities and capacities. High income countries have a more than three times higher rate of antibiotic usage than low and middle income countries [59].

\section{The implications of multidrug resistance for the disruption of invasive cardiovascular procedures}

Simply adding up the numbers of surgeries currently estimated for CABG, PCI, heart transplants, interventional electrophysiological procedures and cardiac valve replacements from the figures above, 2.5-3 million cardiovascular surgical interventions would be expected to occur in the USA alone each year (Table 1). Denying all or even a fraction of these patients access to these, in many cases, lifesaving surgical interventions, would have a drastic effect on the overall health status of Amnericans. Increases in death rates and decreases in average life span, a rise in hospitalization rates and increased length of hospitalization stays would also be expected to develop. One would expect similar implications for the world's population with orders of magnitude greater numbers involved. It is unlikely that the expected global death rate estimated for 2050 described in the preceding section takes into account the diminished, delayed or complete removal of access to life saving cardiovascular surgery that will inevitably accompany the development of bacterial resistance to all antibiotics.

However, is there any emerging evidence of multidrug resistance bacteria appearing in the cardiovascular surgical theatre or is this an idle threat at the present time? A body of data on rapidly spreading multidrug resistance in bacterial species implicated in cardiovascular maladies and invasive treatments is accumulating, including Helicobacter pylori [60], Porphyromonas gingivalis [61] and Chlamydia pneumoniae [62]. In a Brazilian case report, a 59 year old male heart transplant patient went into septic shock and multiple organ failure leading to death 50 days post transplantation due to infection with multidrug resistant Klebsiella pneumonia [63]. In China's Wuhan Hospital, of 299 heart transplant patients, $49.2 \%$ were found to be infected with 259 

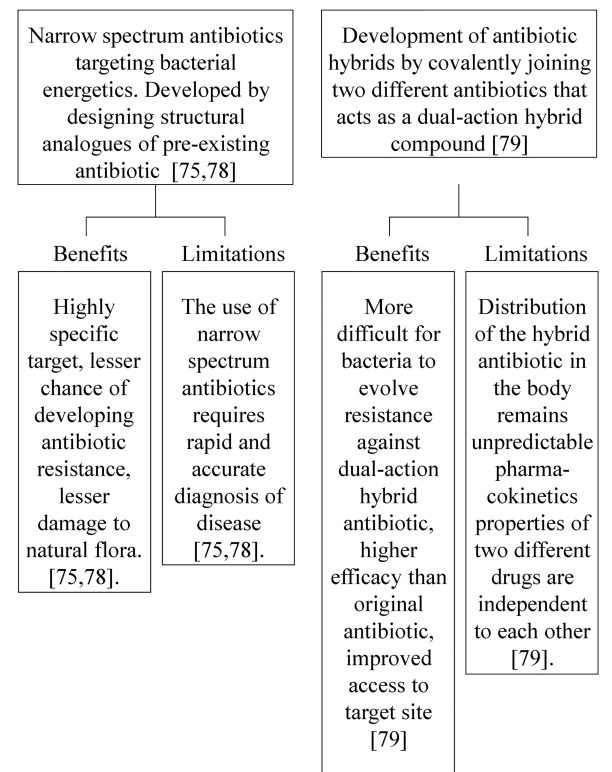
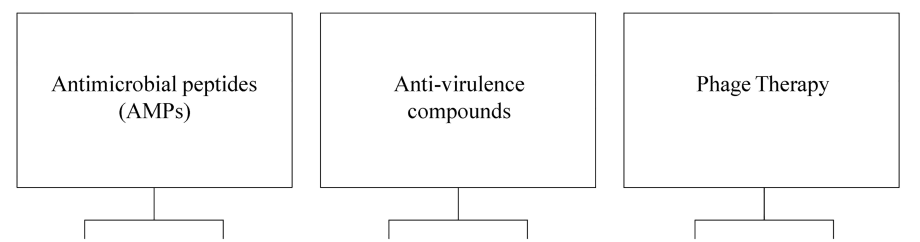

\begin{tabular}{|c|c|}
\hline Benefits & Limitations \\
\hline $\begin{array}{c}\text { Broad } \\
\text { spectrum, } \\
\text { hits } \\
\text { multiple } \\
\text { targets, } \\
\text { modulates } \\
\text { innate } \\
\text { immune } \\
\text { response of } \\
\text { the host to }\end{array}$ & $\begin{array}{c}\text { Lower } \\
\text { stability of } \\
\text { AMPs, very } \\
\text { high cost, } \\
\text { limited } \\
\text { database of } \\
\text { standardized } \\
\text { toxicology } \\
\text { for the AMPs } \\
{[80]}\end{array}$ \\
\hline $\begin{array}{c}\text { facilitate } \\
\text { pathogen } \\
\text { clearance } \\
{[80]}\end{array}$ & \\
\hline
\end{tabular}

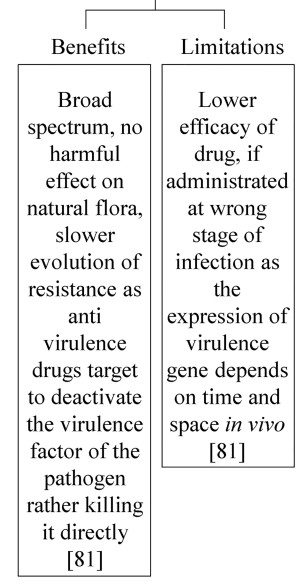

Fig. 1. Current approaches for drug development to combat antibiotic resistance. These strategic approaches include phage therapy, antimicrobial peptides, anti-virulence compounds and the development of novel drug designs.

different pathogens [64]. Of these 147 infected patients, 64 multidrug resistant bacteria were detected within one year after the transplant. Extended spectrum $\beta$-lactamases in Klebsiella pneumonia and methicillin-resistant Staphylococcus aureus were the most common resistant species identified. In India, similar results were reported for their heart transplant patients. Of 149 transplant patients, 31\% reported bacterial infectons within the year following the transplant [65]. Thirty of the 46 infected patients were infected with multidrug resistant bacteria. Again, the most common resistant bacteria were with extended spectrum $\beta$ lactamase and Klebsiella pneumonia but Escheria coli and Pseudomonas aeruginosa were also identified. Bacterial infections were associated with a significantly higher mortality rate versus those without an infection. Extremely drug resistant infections were associated with a 26 fold higher risk of death [65].

The challenge of multidrug resistant bacteria is not restricted to cardiac transplantation surgeries. Patients undergoing a variety of cardiac surgeries (including open heart surgery) have shown evidence of infectious complications with multidrug resistant bacteria varying in incidence from $0.6 \%$ [65] to $10 \%$ [66]. Patients with multidrug resistant infections had a higher mortality rate than those infected with non-multidrug resistant bacteria [66]. More severe illness with multidrug resistant bacteria was also observed [67]. E. coli, S. aureus and Acinetobacter baumannii strains were identified as the multidrug resistant strains present $[67,68]$. Recurrent infections with a multidrug resistant Pseudomonas aeruginosa bacteria has been identified during repeated triscupid valve replacements with aortic valve homografts employed to treat relapsing tricuspid valve en- docarditis [69]. Multidrug resistant P. aeruginosa bacteria have also been identified following implantation with left ventricular assistant devices [70,71]. In pediatric cardiac surgery cases, the rate of multidrug resistant cases was 3.8\% in 2973 patients [72]. Interestingly, multidrug resistant bacteria was more often found in children admitted from other hospitals in comparison to children admitted from home [73]. In clinical samples collected from patients suspected of heart infections, where the majority of the bacteria identified were $E$. coli or K. pneumoniae, $58 \%$ of the gram negative bacteria were resistant to ampicillin and $48 \%$ were resistant to nalidixic acid in susceptibility tests [16]. Over half of the bacterial isolates were multidrug resistant [16]. It is clear from these studies that multidrug resistant bacteria are not only present currently in invasive cardiovascular surgical procedures but its emergence is increasing [68].

\section{The need to address multidrug resistance immediately}

For most of the history of antibiotics, the standard pharmaceitcal approach has been to develop antibiotics that can be used for many situations without the need to first identify the cause (Fig. 1, Ref. [74-82]). These broad-spectrum antibiotics affect unintended and often nonpathogenic bacteria in the environment, which act as reservoirs for the development of multidrug resistance [74]. Broad-spectrum antibiotics also have a huge impact on the human gut microbiota, frequently resulting in an overgrowth of Clostridium difficile [75]. The multiplicity of molecular mechanisms underlying multidrug resistance has led to the search for different approaches in new antiinfectious strategies, including (in the addition to the de- 
velopment of new antibiotics) drug re-purposing. An idea to abate the problem associated with broad spectrum antibiotics is to generate/design narrow-spectrum antibiotics [76]. Narrow-spectrum antibiotics, conversely, are largely ignored by unintended targets and, therefore, would not be expected to have a major impact on multidrug resistance development. In the antibacterial pipeline there has been an upward trend in the development of narrow-spectrum antibiotics [39]. However, the use of narrow-spectrum antibiotics must be coupled with rapid and accurate diagnosis. An innovative idea to overcome existing resistance mechanisms is to produce antibiotic hybrids, which are two different antibiotic types or an antibiotic and an adjuvant covalently bound [77]. Other approaches which are currently being explored include antimicrobial peptides, anti-virulence compounds, phage therapy [78], structural analogues of existing antibiotic platforms and novel platforms of drug development $[76,79]$. However, a new platform for antibiotics has not been introduced into the marketplace for over 40 years. If this continues unabated, pathogenic bacteria will challenge our health care systems as they did in past centuries. An exciting new approach has been to specifically target bacterial energetics instead of the conventional targets of membrane integrity, protein synthesis and DNA replication [76,79]. The inhibition of bacterial respiration represents a novel platform that also enjoys the secondary consequence of inducing cell suicide by the generation of reactive oxygen species [76,79]. However, this approach, like phage therapy and many other novel advances, has yet to be successfully employed clinically.

\section{Conclusions and recommendations}

Pathogenic bacteria, particularly a wide array of gram negative bacteria, continue to represent a challenge to invasive cardiovascular surgery of all kinds and cardiovascular diseases in general. The development of antibiotics that are immune to the resistance currently displayed by pathogenic bacteria will be critical if the fate of cardiovascular surgery is to be retained in even a facsimile of what it is today. The crisis facing the world should bacteria continue to develop resistance to current antibiotic therapies, as is predicted for the future, will revolutionize medicine as it is practiced today. The pharmaceutical industry must meet this impending challenge with novel antibiotic platforms that have the potential to avoid multidrug resistance [76-84].

\section{Author contributions}

GNP created the idea for the manuscript topic, carried out initial research and wrote the first draft. ED, PD, $\mathrm{AR}, \mathrm{CR}$ and $\mathrm{MM}$ contributed to the writing of the paper and provided critical input. MM designed and created the figure. All authors contributed to editorial changes in the manuscript. All authors read and approved the final manuscript.

\section{Ethics approval and consent to participate}

Not applicable.

\section{Acknowledgment}

We would like to express our gratitude to all those who helped us during the writing of this manuscript. Thanks to all the peer reviewers for their opinions and suggestions.

\section{Funding}

This work was supported by a Foundation Grant from CIHR to GNP, and an NSERC grant to PD.

\section{Conflict of interest}

PD is the Chief Scientific Advisor for Viotika Life Sciences, Inc. The authors declare no conflict of interest. Grant N. Pierce is serving as one of the Editorial Board members of this journal. We declare that Grant N. Pierce had no involvement in the peer review of this article and has no access to information regarding its peer review. Full responsibility for the editorial process for this article was delegated to Morris Karmazyn and Victor L. Serebruany.

\section{References}

[1] Caligiuri SPB, Pierce GN. A review of the relative efficacy of dietary, nutritional supplements, lifestyle, and drug therapies in the management of hypertension. Critical Reviews in Food Science and Nutrition. 2017; 57: 3508-3527.

[2] Cohn LH. The first successful surgical treatment of mitral stenosis: the 70th anniversary of Elliot Cutler's mitral commissurotomy. the Annals of Thoracic Surgery. 1993; 56: 1187-1190.

[3] Bourantas CV, Serruys PW. Evolution of transcatheter aortic valve replacement. Circulation Research. 2014; 114: 10371051.

[4] Beck H, Boden WE, Patibandla S, Kireyev D, Gupta V, Campagna F, et al. 50th Anniversary of the first Successful Permanent Pacemaker Implantation in the United States: Historical Review and Future Directions. the American Journal of Cardiology. 2010; 106: 810-818.

[5] Endo M. The history and evolution of coronary artery bypass grafting. Nihon Geka Gakkai Zasshi. 2000; 101: 827-832. (In Japanese)

[6] Colvin M, Smith JM, Hadley N, Skeans MA, Uccellini K, Lehman R, et al. OPTN/SRTR 2017 Annual Data Report: Heart. American Journal of Transplantattion. 2019; 19 Suppl. 2: 323 403.

[7] Everly MJ. Cardiac transplantation in the United States: an analysis of the UNOS registry. Clinical Transplants. 2008; 35-43.

[8] Grech ED. Percutaneous coronary intervention. I: History and development. British Medical Journal. 2003; 326: 1080-1082.

[9] Kiess M. History and evolution of the treatment of adult congenital heart disease. British Columbia Medical Journal. 2016; 58: 368-372.

[10] Ioannou P, Vougiouklakis G, Baliou S, Miliara E, Kofteridis DP. Infective endocarditis by Yersinia species: A systematic review. Tropical Medicine and Infectious Disease. 2021; 6: 19.

[11] Dowling WB and Koen J. Corynebacterium jeikeium native value infective endocarditis case report: a confirmed microbiological and pathological diagnosis from heart valvular tissue. European Heart Journal-Case Reports. 2020; 4: 1-4.

[12] Álvarez P, Fuentes C, García N, Modesto V. Evaluation of the 
duration of the antibiotic prophylaxis in paediatric postoperative heart surgery patients. Pediatric Cardiology. 2012; 33: 735-738.

[13] Ioannou P, Mavrikaki V, Kofteridis DP. Infective endocarditis by Acinetobacter species: a systematic review. Journal of Chemotherapy. 2021; 33: 203-215.

[14] Cairns KA, Hall V, Martin GE, Griffin DWJ, Stewart JD, Khan $\mathrm{SF}$, et al. Treatment of invasive IMP-4 Enterobacter cloacae infection in transplant recipients using ceftazidime/avibactam with aztreonam: A case series and literature review. Transplant Infectious Disease. 2021. 23: e13510.

[15] Iyer RN, Rao JR, Rudramurthy SM, Kapoor D. Two Cases of Nocardia bacteraemia in Solid Organ Transplant Recipients. Indian Journal of Medical Microbiology. 2020; 38: 123-126.

[16] Sah RSP, Dhungel B, Yadav BK, Adhikari N, Shrestha UT, Lekhak B, et al. Detection of TEM and CTX-M Genes in Escherichia coli isolated from clinical specimens at Teritary Care Heart Hospital, Kathmandu, Nepal. Diseases. 2021; 9: 15.

[17] Greve D, Moter A, Kleinschmidt MC, Pfäfflin F, Stegemann MS, Kursawe L, et al. Rothia aeria and Rothia dentocariosa as biofilm builders in infective endocarditis. International Journal of Medical Microbiology. 2021; 311: 151478.

[18] Abdul Salim S, Masoud AT, Thongprayoon C, Cheungpasitporn W, Soliman KM, Garla V, et al. Systematic Review and Meta-Analysis of Antibiotic and Antimicrobial Lock Solutions for Prevention of Hemodialysis Catheter-Related Infections. ASAIO Journal. 2021. (in press)

[19] LoCicero J. Prophylactic antibiotic usage in cardiothoracic surgery. Chest. 1990; 98: 719-723.

[20] Braxton JH, Marrin CAS, McGrath PD, Morton JR, Norotsky M, Charlesworth DC, et al. 10-year follow-up of patients with and without mediastinitis. Seminars in Thoracic and Cardiovascular Surgery. 2004; 16: 70-76.

[21] Anand V, Bates A, Featherstone R, Murthy S. Perioperative antibiotics in pediatric cardiac surgery: protocol for a systematic review. Systematic Reviews. 2017; 6: 107.

[22] Goodman JS, Schaffner W, Collins HA, Battersby EJ, Koenig MG. Infection after Cardiovascular Surgery. New England Journal of Medicine. 1968; 278: 117-123.

[23] Fekety FR, Cluff LE, Sabiston DC, Seidl LG, Smith JW, Thoburn R. A study of antibiotic prophylaxis in cardiac surgery. The Journal of Thoracic and Cardiovascular Surgery. 1969; 57: $757-763$.

[24] Engemann JJ, Carmeli Y, Cosgrove SE, Fowler VG, Bronstein MZ, Trivette SL, et al. Adverse Clinical and Economic Outcomes Attributable to Methicillin Resistance among Patients withStaphylococcus aureusSurgical Site Infection. Clinical Infectious Diseases. 2003; 36: 592-598.

[25] Zanetti G, Goldie SJ, Platt R. Clinical consequences and cost of limiting use of vancomycin for perioperative prophylaxis: example of coronary artery bypass surgery. Emerging Infectious Diseases. 2001;7: 820-827.

[26] Markewitz A, Schulte HD, Scheld HH. Current practice of peri- and postoperative antibiotic therapy in cardiac surgery in Germany. Working Group on Cardiothoracic Surgical Intensive Care Medicine of the German Society for Thoracic and Cardiovascular Surgery. The Thoracic and Cardiovascular Surgeon. 1999; 47: 405-410.

[27] Engleman R, Shahian D, Shemin R, Guy TS, Bratzler D, Edwards F, et al. The Society of Thoracic Surgeons Practice Guidelines Series: Antibiotics prophylaxis in cardiac surgery, Part II: Antibiotic choice. The Annals of Thoracic Surgery. 2007; 83: 1569-1576.

[28] Paling FP, Olsen K, Ohneberg K, Wolkewitz M, Fowler VG, DiNubile MJ, et al. Risk prediction for Staphylococcus aureus surgical site infection following cardiothoracic surgery; a secondary analysis of the V710-P003 trial. PloS one. 2018; 13: e0193445.

[29] Engelman DT, Ben Ali W, Williams JB, Perrault LP, Reddy VS, Arora RC, et al. Guidelines for Perioperative Care in Cardiac Surgery. JAMA Surgery. 2019; 154: 755-766.

[30] Al-Momany NH, Al-Bakri AG, Makahleh ZM, Wazaify MMB. Adherence to international antimicrobial prophylaxis guidelines in cardiac surgery: a Jordanian study demonstrates need for quality improvement. Journal of Managed Care Pharmacy. 2009; 15: 262-271.

[31] Edwards FH, Engelman RM, Houck P, Sanan DM, Bridges ChR. The Society of Thoracic Surgeons practice guidelines series: antibiotic prophylaxis in cardiac surgery, part I: duration. The Annals of Thoracic Surgery. 2006; 81: 397-404.

[32] Hidalgo-Tenorio C, Gálvez J, Martínez-Marcos FJ, Plata-Ciezar A, De La Torre-Lima J, López-Cortés LE, et al. Clinical and prognostic differences between methicillin-resistant and methicillin-susceptible Staphylococcus aureus infective endocarditis. BMC Infectious Diseases. 2020; 20: 160.

[33] World Health Organization. Antimicrobial Resistance: Global Report on Surveillance. WHO Press: Geneva, Switzerland. 2014.

[34] World Health Organization. Antimicrobial resistance. 2020. Available at: https://www.who.int/news-room/fact-sheets/deta il/antimicrobial-resistance (Accessed: 15 October 2020).

[35] Smith PW, Watkins K, Hewlett A. Infection control through the ages. American Journal of Infection Control. 2012; 40: 35-42.

[36] Abraham EP, Chain E. An enzyme from bacteria able to destroy penicillin. 1940. Reviews of Infectious Diseases. 1988; 10: 677678.

[37] Rex JH. What does an antibiotic cost to develop? What is it worth? How to afford it? 2020. Available at: https://amr.solutions/2020/03/06/what-does-an-antibiotic-cos t-to-develop-what-is-it-worth-how-to-afford-it/ (Accessed: 16 September 2020).

[38] Klemm EJ, Wong VK, Dougan G. Emergence of dominant multidrug-resistant bacterial clades: Lessons from history and whole-genome sequencing. Proceedings of the National Academy of Sciences of the United States of America. 2018; 115: $12872-12877$.

[39] Theuretzbacher U, Outterson K, Engel A, Karlén A. The global preclinical antibacterial pipeline. Nature Reviews Microbiology. 2020; 18: 275-285.

[40] Centers for Disease Control and Prevention. Antibiotic resistance threats in the United States, 2013. 2013. Available at: ht tps://www.cdc.gov/drugresistance/pdf/ar-threats-2013-508.pdf (Accessed: 14 May 2020).

[41] Centers for Disease Control and Prevention. Antibiotic resistance threats in the United States, 2019. 2019. Available at: https://www.cdc.gov/drugresistance/Biggest-Threats.html (Accessed: 12 October 2020).

[42] Council of Canadian Academies Report. When antibiotics fail. Public Health Agency of Canada: Ottawa, Canada. 2019.

[43] O'Neill J. Tackling drug-resistant infections globally: final report and recommendations. Wellcome Trust: UK. 2016.

[44] Ginsburg AS, Klugman KP. COVID-19 pneumonia and the appropriate use of antibiotics. the Lancet Global Health. 2020; 8: e1453-e1454.

[45] Sengupta S, Chattopadhyay MK, Grossart H. The multifaceted roles of antibiotics and antibiotic resistance in nature. Frontiers in Microbiology. 2013; 4: 47.

[46] Nikaido H. Multidrug Resistance in Bacteria. Annual Review of Biochemistry. 2009; 78: 119-146.

[47] Chang H, Cohen T, Grad YH, Hanage WP, O’Brien TF, Lipsitch $\mathrm{M}$. Origin and proliferation of multiple-drug resistance in bacterial pathogens. Microbiology and Molecular Biology Reviews. 2015; 79: 101-116. 
[48] Blanco P, Hernando-Amado S, Reales-Calderon JA, Corona F, Lira F, Alcalde-Rico M, et al. Bacterial Multidrug Efflux Pumps: much more than Antibiotic Resistance Determinants. Microorganisms. 2016; 4: 14.

[49] Kanchugal P S, Selmer M. Structural Recognition of Spectinomycin by Resistance Enzyme ANT(9) from Enterococcus faecalis. Antimicrobial Agents and Chemotherapy. 2020; 64: e00371-20.

[50] Morens DM, Taubenberger JK, Fauci AS. Predominant role of bacterial pneumonia as a cause of death in pandemic influenza: implications for pandemic influenza preparedness. The Journal of Infectious Diseases. 2008; 198: 962-970.

[51] Chien Y, Klugman KP, Morens DM. Bacterial pathogens and death during the 1918 influenza pandemic. The New England Journal of Medicine. 2009; 361: 2582-2583.

[52] Sheng Z, Chertow DS, Ambroggio X, McCall S, Przygodzki RM, Cunningham RE, et al. Autopsy series of 68 cases dying before and during the 1918 influenza pandemic peak. Proceedings of the National Academy of Sciences of the United States of America. 2011; 108: 16416-16421.

[53] Armitage R, Nellums LB. Antibiotic prescribing in general practice during COVID-19. The Lancet Infectious Diseases. 2021; 21: e144.

[54] Beović B, Doušak M, Ferreira-Coimbra J, Nadrah K, Rubulotta $\mathrm{F}$, Belliato M, et al. Antibiotic use in patients with COVID-19: a 'snapshot' Infectious Diseases International Research Initiative (ID-IRI) survey. Journal of Antimicrobial Chemotherapy. 2020; 75: 3386-3390.

[55] Rawson TM, Moore LSP, Zhu N, Ranganathan N, Skolimowska $\mathrm{K}$, Gilchrist $\mathrm{M}$, et al. Bacterial and fungal coinfection in individuals with coronavirus: a rapid review to support COVID-19 antimicrobial prescribing. Clinical Infectious Diseases. 2020; 71 : 2459-2468.

[56] Langford BJ, So M, Raybardhan S, Leung V, Soucy JR, Westwood D, et al. Antibiotic prescribing in patients with COVID19: rapid review and meta-analysis. Clinical Microbiology and Infection. 2021; 27: 520-531.

[57] Strathdee SA, Davies SC, Marcelin JR. Confronting antimicrobial resistance beyond the COVID-19 pandemic and the 2020 us election. The Lancet. 2020; 396: 1050-1053.

[58] Vijay S, Bansal N, Rao BK, Veeraraghavan B, Rodrigues C, Wattal C, et al. Secondary infections in hospitalized COVID-19 patients:Indian experience. Infection and Drug Resistance. 2021; 14: 1893-1903.

[59] Browne AJ, Chipeta MG, Haines-Woodhouse G, Kumaran EPA, Hamadani BHK, Zaraa S, et.al. Global antibiotic consumption and usage in humans, 2000-18: a spatial modelling study. Lancet Planet Health. 2021; 5: e893-e904.

[60] Mégraud F. The challenge of Helicobacter pylori resistance to antibiotics: the comeback of bismuth-based quadruple therapy. Therapeutic Advances in Gastroenterology. 2012; 5: 103-109.

[61] Ardila CM, López MA, Guzmán IC. High resistance against clindamycin, metronidazole and amoxicillin in Porphyromonas gingivalis and Aggregatibacter actinomycetemcomitans isolates of periodontal disease. Medicina Oral, Patologia Oral Y Cirugia Bucal. 2010; 15: e947-e951.

[62] Borel N, Leonard C, Slade J, Schoborg RV. Chlamydial Antibiotic Resistance and Treatment Failure in Veterinary and Human Medicine. Current Clinical Microbiology Reports. 2016; 3: 1018.

[63] Galvão LM, Oliveira APRD, Ibanês AS, Monteiro J, Inoue F, Dantas DC, et al. Fatal case of donor-derived colistin-resistant carbapenemase-producing Klebsiella pneumoniae transmission in cardiac transplantation. The Brazilian Journal of Infectious Diseases. 2018; 22: 235-238.

[64] Zhou Y, Cai J, Wang X, Du S, Zhang J. Distribution and re- sistance of pathogens in infected patients within 1 year after heart transplantation. International Journal of Infectious Diseases. 2020; 103: 132-137.

[65] Bhatt PJ, Ali M, Rana M, Patel G, Sullivan T, Murphy J, et al. Infections due to multidrug-resistant organisms following heart transplantation: Epidemiology, microbiology, and outcomes. Transplant Infectious Disease. 2020; 22: e13215.

[66] Ko RE, Huh K, Kim DH, Na SJ, Chung CR, Cho YH, et al. Nosocomial infections in in-hospital cardiac arrest patients who undergo extracorporeal cardiopulmonary resuscitation. PLoS One. 2020; 15: e0243838.

[67] Pierri MD, Crescenzi G, Capestro F, Recanatini C, Manso E, D'errico MM, et al. Risk Factors and Impact on Clinical Outcome of Multidrug-Resistant Acinetobacter Baumannii Acquisition in Cardiac Surgery Patients. Journal of Cardiothoracic and Vascular Anesthesia. 2016; 30: 680-686.

[68] Davoudi A, Najafi N, Alian S, Tayebi A, Ahangarkani F, Rouhi $\mathrm{S}$, et al. Resistance Pattern of Antibiotics in Patient Underwent Open Heart Surgery with Nosocomial Infection in North of Iran. Global Journal of Health Science. 2015; 8: 288-297.

[69] Kim M, Chang HW, Lee S, Kang DK, Kim E, Kim K. Relapsing tricuspid valve endocarditis by multidrug-resistant Pseudomonas aeruginosa in 11 years: tricuspid valve replacement with an aortic valve homograft. Journal of Cardiothoracic Surgery. 2015; 10: 82.

[70] Aye C, Williams M, Horvath R. Multidrug Resistant Pseudomonas Mycotic Pseudoaneurysm following Cardiac Transplant Bridged by Ventricular Assistant Device. Case Reports in Infectious Diseases. 2017; 2017: 1402320.

[71] Peghin M, Maiani M, Castaldo N, Givone F, Righi E, Lechiancole A, et al. Ceftolozane/tazobactam for the treatment of MDR Pseudomonas aeruginosa left ventricular assist device infection as a bridge to heart transplant. Infection. 2018; 46: 263-265.

[72] Sun L, Liu S, Wang J, Wang L. Analysis of Risk Factors for Multiantibiotic-Resistant Infections among Surgical Patients at a Children's Hospital. Microbial Drug Resistance. 2019; 25: $297-$ 303.

[73] Jaworski R, Haponiuk I, Steffens M, Arlukowicz E, IrgaJaworska N, Chojnicki M, et al. Colonization of multidrug resistant pathogens in a hybrid pediatric cardiac surgery centre. Archives of Medical Science. 2016; 12: 639-644.

[74] Melander RJ, Zurawski DV, Melander C. Narrow-spectrum antibacterial agents. MedChemComm. 2018; 9: 12-21.

[75] Alm RA, Lahiri SD. Narrow-spectrum antibacterial agentsbenefits and challenges. Antibiotics. 2020; 9: 418.

[76] Dibrov P, Dibrov E, Maddaford TG, Kenneth M, Nelson J, Resch $\mathrm{C}$, et al. Development of a novel rationally designed antibiotic to inhibit a nontraditional bacterial target. Canadian Journal of Physiology and Pharmacology. 2017; 95: 595-603.

[77] Datta P, Gupta V. Next-generation strategy for treating drug resistant bacteria: Antibiotic hybrids. Indian Journal of Medical Research. 2019; 149: 97-106

[78] Pacios O, Blasco L, Bleroit I, Fernandez-Garcia L, Bardanca MG, Ambroa A, et al. Strategies to combat multidrug-resistant and persistent infectious diseases. Antibiotics. 2020; 9: 65-85.

[79] Dibrov P, Dibrov E, Pierce GN. Na+-NQR (Na+-translocating NADH: ubiquinone oxidoreductase) as a novel target for antibiotics. FEMS Microbiology Reviews. 2017; 41: 653-671.

[80] Theuretzbacher U. Dual-mechanism antibiotics. Nature Microbiology. 2020; 5: 984-985.

[81] Mahlapuu M, Håkansson J, Ringstad L, Björn C. Antimicrobial Peptides: an Emerging Category of Therapeutic Agents. Frontiers in Cellular and Infection Microbiology. 2016; 6: 194.

[82] Totsika M. Benefits and Challenges of Antivirulence Antimicrobials at the Dawn of the Post-Antibiotic Era. Drug Delivery Letters. 2016; 6: 30-37. 
[83] Loc-Carrillo C, Abedon ST. Pros and cons of phage therapy. Bacteriophage. 2011; 1: 111-114.

[84] Privalsky TM, Soohoo AM, Wang JH, Walsh CT, Wright GD,
Gordon EM, et.al. Prospects for antibacterial discovery and development. Journal of the American Chemical Society. 2021; 143: 21127-21142. 